\title{
Regroupement des militants syndicaux
}

\author{
(1979)
}

\section{Cahier du RMS no 6}

\author{
Les syndicats au Québec \\ et les prochaines élections fédérales
}

Un document produit en version numérique par Jean-Marie Tremblay, bénévole, professeur de sociologie retraité du Cégep de Chicoutimi

Courriel: jean-marie_tremblay@uqac.ca

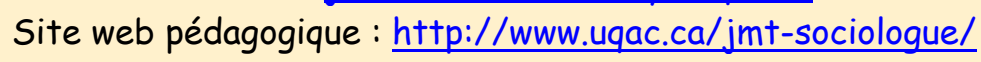

Dans le cadre de: "Les classiques des sciences sociales"

Une bibliothèque numérique fondée et dirigée par Jean-Marie Tremblay,

professeur de sociologie au Cégep de Chicoutimi

Site web: http://classiques.uqac.cal

Une collection développée en collaboration avec la Bibliothèque

Paul-Émile-Boulet de l'Université du Québec à Chicoutimi

Site web: $\underline{h t+p: / / b i b l i o t h e q u e . u q a c . c a /}$ 


\section{Politique d'utilisation de la bibliothèque des Classiques}

Toute reproduction et rediffusion de nos fichiers est interdite, même avec la mention de leur provenance, sans l'autorisation formelle, écrite, du fondateur des Classiques des sciences sociales, Jean-Marie Tremblay, sociologue.

Les fichiers des Classiques des sciences sociales ne peuvent sans autorisation formelle:

- être hébergés (en fichier ou page web, en totalité ou en partie) sur un serveur autre que celui des Classiques.

- servir de base de travail à un autre fichier modifié ensuite par tout autre moyen (couleur, police, mise en page, extraits, support, etc...),

Les fichiers (.html, .doc, .pdf, .rtf, .jpg, .gif) disponibles sur le site Les Classiques des sciences sociales sont la propriété des Classiques des sciences sociales, un organisme à but non lucratif composé exclusivement de bénévoles.

Ils sont disponibles pour une utilisation intellectuelle et personnelle et, en aucun cas, commerciale. Toute utilisation à des fins commerciales des fichiers sur ce site est strictement interdite et toute rediffusion est également strictement interdite.

L'accès à notre travail est libre et gratuit à tous les utilisateurs. C'est notre mission.

Jean-Marie Tremblay, sociologue

Fondateur et Président-directeur général, LES CLASSIQUES DES SCIENCES SOCIALES. 
Cette édition électronique a été réalisée par Jean-Marie Tremblay, bénévole, professeur de sociologie au Cégep de Chicoutimi à partir de :

Regroupement des militants syndicaux

Cahier du RMS no 6.

Les syndicats au Québec et les prochaines élections fédérales.

- Pour l'abrogation de l'AANB!

- Pour l'indépendance du Québec!

- Pour la satisfaction des revendications des travailleurs.

Montréal : Regroupement des militants syndicaux, 5 mars 1979, $16 \mathrm{pp}$.

[Autorisation formelle accordée par Louis Gill le 7 janvier 2003 de diffuser ce document dans Les Classiques des sciences sociales.]

Courriel : gill.louis@ugam.ca

Polices de caractères utilisée: Comic Sans, 12 points.

Édition électronique réalisée avec le traitement de textes Microsoft Word 2008 pour Macintosh.

Mise en page sur papier format : LETTRE US, $8.5^{\prime \prime} \times 11^{\prime \prime}$.

Édition numérique réalisée le 2 juillet 2011 à Chicoutimi, Ville de Saguenay, Québec.

f. Fait avec

Macintosh 


\section{Regroupement des militants syndicaux}

Cahier du RMS no 3.

Les syndicats au Québec

et les prochaines élections fédérales.

- Pour l'abrogation de l'AANB !

- Pour l'indépendance du Québec !

- Pour la satisfaction des revendications des travailleurs.

REGROUPEMENT DES MILITANTS SYNDICAUX

Cahier du

RMS no. 6

Les syndicats au Québec et les prochaines élections fédérales

- Pour l'abrogation de l'AANB !

- Pour l'Indépendance du Québec !

- Pour la satisfaction des revendications des travailleurs !

Montréal: Regroupement des militants syndicaux, 5 mars 1979, $16 \mathrm{pp}$. 


\title{
Table des matières
}

\author{
Les syndicats au Québec \\ et les prochaines élections fédérales
}

- Élections fédérales et référendum : des échéances décisives pour

les travailleurs

- 500 militants lancent un appel aux syndicats

- Pour une alternative ouvrière aux prochaines élections

\section{Le rôle du mouvement ouvrier face aux prochaines élections fédérales}

- L'enjeu des prochaines élections fédérales

- La défense du droit à l'autodétermination exige l'abrogation de I'AANB

- Tous les partis fédéraux sont contre le droit à l'autodétermination

- La politique du gouvernement Lévesque

- Contrer le chantage terroriste des fédéralistes

- 75 candidats des organisations ouvrières 


\title{
Les syndicats au Québec et les prochaines élections fédérales
}

\author{
Élections fédérales et référendum : \\ des échéances décisives pour les travailleurs
}

Retour à la table des matières

Nous sommes à quelques semaines des élections fédérales les plus importantes de I'histoire du Canada et du Québec: nous sommes à quelques mois du référendum où est enjeu l'avenir du Québec. Ces enjeux et échéances sont d'une importance décisive pour les travailleurs.

Alors que les adversaires de I'Indépendance du Québec se structurent et s'organisent, que la coalition des forces fédéralistes se consolide, la nécessité d'une riposte unitaire du mouvement ouvrier se pose d'une manière de plus en plus aiguë.

La campagne pré-référendaire est bel et bien engagé et les prochaines élections fédérales s'en viennent à grands pas. À l'heure où le Parti Libéral de Trudeau, le Parti Conservateur de Clark, le Parti Libéral de Ryan, le Comité ProCanada, mobilisent leurs millions de dollars en propagande et veulent tout faire pour empêcher le peuple du Québec de disposer librement de lui-même, cette offensive en règle ne peut rester sans réplique. Or, qui peut organiser cette réplique si ce 
n'est les organisations des travailleurs et au premier titre les syndicats?

[4]

\section{0 militants lancent un appel aux syndicats}

Le mouvement ouvrier peut et doit prendre l'initiative de la riposte contre ces attaques et cette propagande fédéraliste de la coalition anti-Québec. Nous croyons que les centrales syndicales et nos syndicats doivent organiser une campagne publique sur ce qu'est vraiment l'État fédéral canadien comme pilier de l'exploitation des travailleurs et de l'oppression du peuple du Québec. Nous croyons que cette campagne devrait culminer dans la convocation des États Généraux du mouvement syndical pour les droits du peuple du Québec et les revendications des travailleurs.

C'est en ce sens qu'à la mi-février, 40 militants de différents syndicats, secteurs, fédérations, membres du Regroupement des Militants Syndicaux ou s'associant à eux, lançaient un APPEL AUX SYNDICATS pour que s'organise cette riposte du mouvement syndical : deux semaines plus tard, 500 autres militants s'ajoutaient aux premiers signataires de l'APPEL.

\section{Pour une alternative ouvrière aux prochaines élections}

\section{Retour à la table des matières}

Les prochaines élections fédérales sont prévues pour ce printemps. À l'approche de cette échéance qui devient de plus en plus pressante, des questions de toute première importance se posent : quelle alternative s'offre aux travailleurs, aux Québécois, face aux partis fédéralistes anti-Québécois de Trudeau et de Clark? Que fera le mouvement 
ouvrier dans ces élections face aux partis anti-travailleurs et antiQuébécois? Peut-il laisser Trudeau et ses candidats, Clark et les siens se disputer seuls les votes des travailleurs du Québec?

Nous croyons pour notre part que nos organisations syndicales doivent prendre l'initiative d'offrir une alternative de vote aux travailleurs contre les Trudeau et les Clark. Nous [5] pensons que la présentation d'un bloc de candidats des travailleurs dans les 75 comtés fédéraux du Québec, appuyés activement par des milliers de militants du mouvement ouvrier, serait aujourd'hui l'alternative la plus claire à offrir pour permettre aux travailleurs, au peuple du Québec, de concentrer leurs voix contre la coalition fédéraliste anti-québécoise et antiouvrière.

Le RMS est d'avis que cette question mérite d'être discutée le plus largement possible dans les organisations ouvrières et soumet dans cette brochure sa contribution à ce débat ${ }^{1}$.

5 mars 1979

1 Cette contribution du RMS a été adoptée par I'Assemblée du RMS du 23 janvier dernier comme aboutissement d'une discussion amorcée en décembre dans les rangs du RMS à partir d'un document Intitulé « Le rôle du mouvement ouvrier face aux prochaines élections fédérales » et diffusé à l'ensemble de ses militants. 

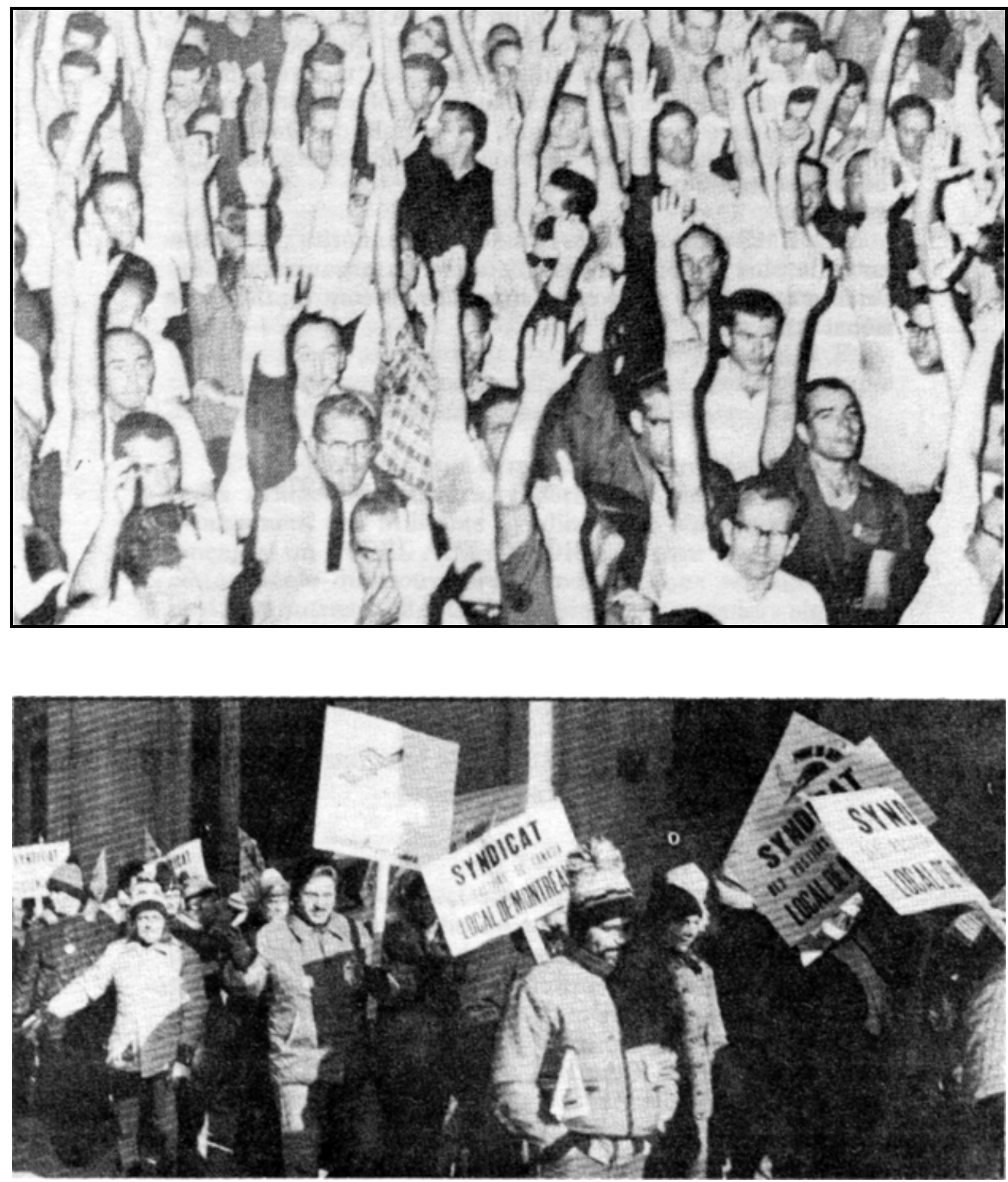

La grève des postiers, l'automne dernier, menaçait directement la survie du gouvernement de faillite de Trudeau, organisateur de l'inflation, du chômage, des coupures dans les budgets sociaux, du gel des salaires... 


\section{Le rôle}

\section{du mouvement ouvrier face aux prochaines élections fédérales}

L'enjeu des prochaines élections fédérales

\section{Retour à la table des matières}

L'enjeu politique fondamental des prochaines élections fédérales pour les travailleurs est clair. Ces élections sont tout entières dirigées contre les revendications de la classe ouvrière de tout le Canada et contre les aspirations nationales du peuple du Québec, contre son droit à l'autodétermination.

En témoignent l'attaque contre la classe ouvrière qu'exprime la loi adoptée par le gouvernement Trudeau le printemps dernier, retirant le droit de grève aux postiers de tout le Canada pendant une période électorale, la volonté du gouvernement Trudeau d'étendre cette agression à tous les travailleurs de la fonction publique. 
En témoigne le report des élections fédérales, le fait que Trudeau s'accroche au pouvoir allant jusqu'à l'extrême limite de son mandat électoral de 5 ans, en rupture avec les traditions parlementaires canadiennes qui fixent à 4 ans la durée effective des mandats. Trudeau savait au printemps dernier que s'il déclenchait des élections, il serait battu. Aujourd'hui comme hier, la défaite de Trudeau signifierait un affaiblissement de l'État fédéral. Trudeau tente de se donner les [8] moyens de faire une élection qui va renforcer son État, renforcer la capacité du gouvernement central d'attaquer la classe ouvrière canadienne, de réprimer les aspirations nationales des Québécois. Le gouvernement Trudeau veut regrouper les forces fédéralistes, les rassembler autour d'un plan d'attaque défini, tenter de se servir des prochaines élections comme d'un centre de ralliement pour sonner la charge contre la classe ouvrière, ses aspirations, ses revendications et tenter de faire refluer au Québec, la lutte engagée contre l'oppression nationale.

En témoigne également, l'offensive en règle (loi spéciale, amendes, peines d'emprisonnement, menaces de congédiement massif) menée l'automne dernier contre les postiers en grève, qui menaçaient directement la survie de ce gouvernement de faillite, organisateur de l'inflation, du chômage, des coupures dans les budgets sociaux, du gel des salaires...

Il est évident qu'on va essayer de se servir des élections fédérales pour «bousculer le Québec », y semer la panique, le faire voter sous l'emprise de la peur, tenter à nouveau de lui passer une camisole de force. Les propos maintes fois exprimés par Trudeau, les menaces de recours à l'année, les références aux événements d'octobre 1970, à la loi des mesures de guerre, ne peuvent laisser de doute à ce sujet. Il s'agit d'une orientation nettement définie. 


\section{La défense du droit à l'autodétermination exige l'abrogation de l'AANB}

\section{Retour à la table des matières}

Trudeau menace de faire intervenir l'armée au Québec si le peuple du Québec décide de se séparer «illégalement » dit-il. Mais l'Acte de l'Amérique du Nord Britannique (AANB), loi anti-démocratique adoptée en secret par le Parlement de Londres en 1867, sans aucune consultation de la population du pays, nie par le fait même tout droit « légal » à l'exercice du droit à l'autodétermination, tout droit à la constitution d'un État séparé au Québec ou ailleurs au Canada.

[9]

Par son gouverneur-général non-élu, chef de l'État canadien, incarnation de "l'unité » du pays et existant essentiellement pour sa défense, possédant les pouvoirs de sanction des lois, de dissolution du Parlement 2 et de désignation du Premier ministre, I'AANB prévoit et confie à un seul homme des pouvoirs soustrayant toute possibilité « légale » de séparation à une province. Les pouvoirs monarchiques du gouverneur-général, vice-roi du pays, dont l'existence par ailleurs ne se justifie que par et pour l'« unité » du pays et la défense de l'État fédéral, lui permettent de recourir aux moyens nécessaires, y compris la force, pour empêcher l'acte, déclaré illégal, que serait la rupture de cette unité sans laquelle il n'a plus de raison d'être.

En somme, I'AANB, loi fondamentale du pays qui constitue l'État fédéral canadien, nie le droit à l'autodétermination du peuple du Québec. La défense du droit à l'autodétermination exige donc qu'on réclame l'abrogation de l'AANB. On ne peut logiquement prétendre défendre le droit à l'autodétermination du Québec et vouloir laisser en

2 Ce pouvoir n'est pas du tout illusoire, contrairement à ce que certains seraient enclins à croire. A preuve, la dissolution en 1972, du gouvernement travailliste australien par le gouverneur général d'Australie, représentant de la reine d'Angleterre, ou vice-roi, au même titre que le gouverneur général du Canada. Cette dissolution est survenue dans une période de crise dont l'ampleur n'avait rien de commun avec ce que sera la crise de l'unité canadienne dans l'éventualité où le Québec déciderait librement de se séparer. 
place l'AANB, loi définissant la structure de l'État fédéral centralisateur et oppresseur qui nie ce droit.

\section{Tous les partis fédéraux sont contre le droit à l'autodétermination}

\section{Retour à la table des matières}

À l'approche des élections fédérales, tous les partis politiques fédéraux mènent campagne pour le maintien de cet État fédéral ; tous nient le droit du Québec à l'autodétermination, le droit des Québécois à un État national distinct: tous sont membres du comité préréférendaire pour la défense de [12] I'unité canadienne, le Comité ProCanada, qui annonce son intention de ne pas respecter le droit du Québec à constituer un État séparé, quelque soit le résultat d'une éventuelle décision démocratique en ce sens. De façon scandaleuse, les dirigeants du NPD ont amené leur propre parti au sein de ce même comité avec les représentants toutes couleurs de la bourgeoisie, montrant encore une fois non seulement qu'ils se refusent à prendre en charge la lutte pour la défense des droits nationaux des Québécois, mais qu'ils se rangent ouvertement du côté de ceux qui nient, bafouent quotidiennement ces droits.

Il n'y a donc pas de choix possible pour les travailleurs du Québec entre les divers partis en présence. Aucun d'eux ne constitue une alternative sur cet enjeu central des droits nationaux des Québécois dans les prochaines élections. Dans le cadre des élections fédérales, comme dans le cadre plus général de la défense des droits nationaux des Québécois, les travailleurs et leurs organisations doivent prendre à leur charge la défense pleine et entière du libre droit à l'autodétermination du peuple du Québec, à la libre disposition de son avenir, de son destin politique.

Les travailleurs et leurs organisations doivent tout mettre en oeuvre, dans ces élections fédérales, pour faire entendre leur voix indépendante et offrir une alternative aux masses du Québec. 
[10]

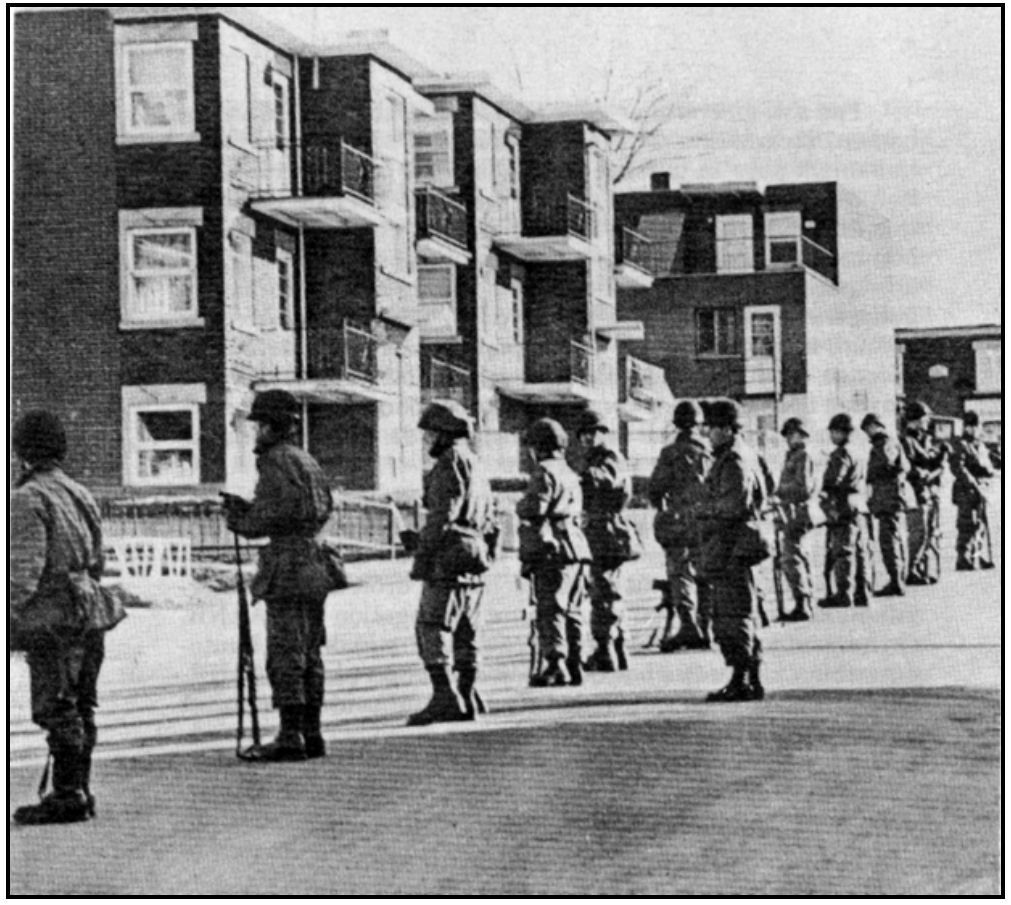

L'armée au Québec sous la Loi des Mesures de Guerre en 1970

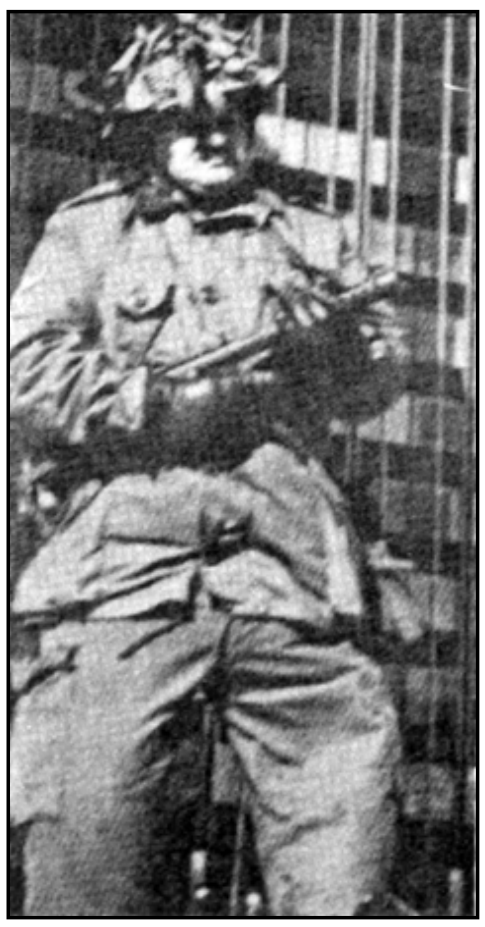

Trudeau menace de faire intervenir l'armée au Québec si le peuple du Québec décide de se séparer « illégalement» dit-il. Mais I'Acte de I'Amérique du Nord Britannique [AANB], loi antidémocratique adoptée en secret par le Parlement de Londres en 1867, sans aucune consultation de la population du pays, nie par le fait même tout droit « légal » à l'exercice du droit à l'autodétermination, tout droit à la constitution d'un État séparé au Québec ou ailleurs au Canada. 


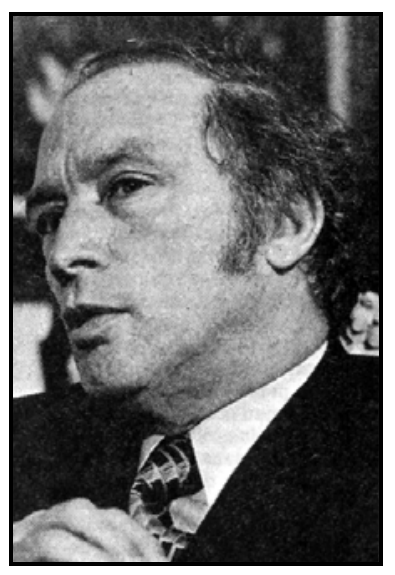

Tous les partis fédéraux sont contre le droit du Québec à disposer librement de lui-même.

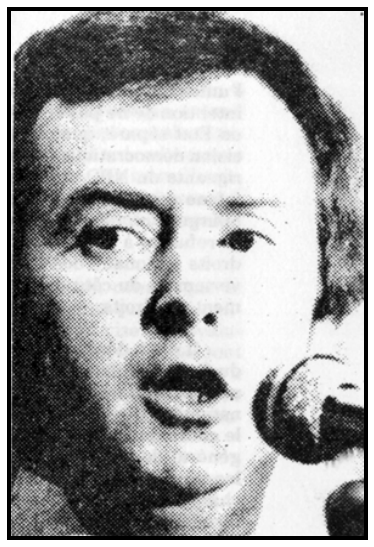

Trudeau, Clark, Ryan, le Comité Pro-Canada mobilisent leurs millions en propagande pour empêcher le peuple du Québec de disposer librement de lui-même.

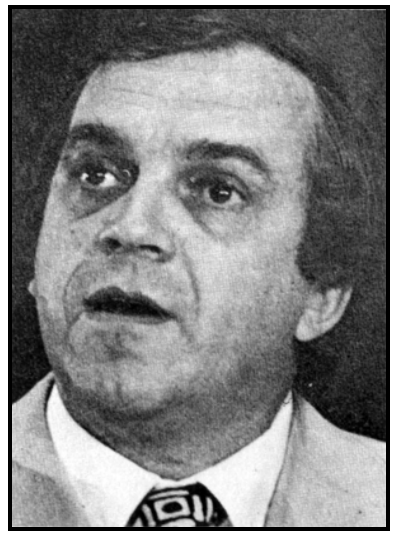

Les dirigeants du NPD ont amené leur parti eu sein du Comité Pro-Canada, se sont joints à la coalition fédéraliste anti-québécoise, se rangeant ouvertement du côté des représentants toutes couleurs de la bourgeoisie qui nient le droit du Québec à l'autodétermination. 


\section{La politique du gouvernement Lévesque}

\section{Retour à la table des matières}

La politique du gouvernement Lévesque face aux attaques de tous les défenseurs de l'État fédéral est une politique de faillite complète. Jour après jour, le gouvernement Lévesque multiplie les signes de compromission, recule devant les exigences des fédéralistes. La dissolution complète de la souveraineté dans l'association en est le dernier exemple.

Le gouvernement Lévesque veut empêcher toute mobilisation de la population du Québec dans la défense de leurs [13] aspirations nationales, dans leur combat pour mettre fin à l'oppression nationale. Le gouvernement Lévesque entend empêcher toute expression indépendante des organisations ouvrières sur la question nationale comme il entend enrayer toute tentative d'action politique autonome des travailleurs. Tel est le sens des lois 92 sur les consultations populaires et 2 sur le financement des partis politiques, dont le maître d'oeuvre a été Robert Burns.

Dans les prochaines élections fédérales, comme par le passé, le gouvernement Lévesque entend pratiquer une politique nationaliste d'abstention effective, qui vise à convaincre les travailleurs et la population du Québec qu'ils ne sont pas concernés par ces élections. Cette politique aboutit à laisser libre jeu aux menées de Trudeau et compagnie, livre le territoire du Québec aux menaces, au chantage, au terrorisme des défenseurs du fédéralisme.

\section{Contrer le chantage terroriste des fédéralistes}

La seule réaction véritablement efficace contre ces menées terroristes ne peut provenir que des organisations ouvrières unies, s'appuyant sur les aspirations des larges masses du Québec. 
Nous devons partir du vote des délégués au dernier congrès du Conseil Central de Montréal (CSN) en faveur de I'Indépendance du Québec et de la lutte pour une organisation politique autonome des travailleurs. Nous devons partir du vote des délégués au congrès de la CEQ se prononçant pour I'Indépendance du Québec, des délégués au dernier congrès de la CSN votant pour le droit du peuple du Québec à un État national. Nous devons partir de la question posée par le Conseil Central de Montréal dans son numéro spécial du Journal Unité Ouvrière à propos de la fermeture de l'usine Cadbury : le CCSNM écrit : « La bourgeoisie du Canada développe une stratégie terroriste. Elle se concerte pour faire payer aux Québécois leur désir légitime de se donner un cadre politique différent, dans lequel elle risque peut-être d'avoir moins [14] de pouvoir. Nous devons arrêter ce chantage terroriste. Comment?»

Comment arrêter ce chantage terroriste qui, demain ira en s'amplifiant?

Le RMS juge nécessaire que s'engage dès aujourd'hui la bataille pour la constitution du Front Uni des organisations ouvrières contre les attaques des défenseurs de l'État fédéral oppresseur, que se crée le Front commun des organisations ouvrières pour la défense du droit à l'autodétermination du Québec, pour l'abrogation de l'AANB.

Ce combat s'inscrit dans le combat pour la formation d'un parti des travailleurs fondé sur leurs organisations, c'est-à-dire pour que les travailleurs se donnent leur propre parti, leur permettant de prendre en charge, au niveau politique, la lutte pour la satisfaction des aspirations nationales des Québécois et des intérêts des travailleurs.

\section{5 candidats des organisations ouvrières}

\section{Retour à la table des matières}

Dans le cadre de ce combat pour la constitution du front uni des organisations ouvrières contre les attaques de tous ceux qui nient au peuple du Québec le droit de disposer librement de lui-même, le RMS croit que les organisations syndicales doivent prendre l'initiative d'of- 
frir une alternative de vote aux travailleurs par la présentation de ses propres candidats dans les 75 comtés du Québec aux prochaines élections fédérales sous la bannière de la lutte pour le droit à l'autodétermination, pour l'abrogation de l'AANB et pour la satisfaction des revendications des travailleurs.

Le RMS est d'avis que la présentation d'un bloc de candidats des travailleurs dans les 75 comtés fédéraux du Québec, appuyés activement par des milliers de militants du mouvement ouvrier, serait aujourd' hui l'alternative la plus claire à offrir aux travailleurs, au peuple du Québec, pour leur permettre de concentrer leurs voix contre la coalition [15] fédéraliste anti-québécoise et anti-ouvrière.

Contre l'État fédéral, pour I'Indépendance du Québec, le RMS dit:

- Front commun des organisations ouvrières contre la coalition fédéraliste anti-québécoise

- États Généraux du mouvement syndical pour les droits du peuple du Québec et les revendications des travailleurs

- Candidats des travailleurs dans les 75 comtés aux prochaines élections fédérales

Sur la plate-forme suivante:

- Satisfaction des revendications ouvrières

- Droit à l'autodétermination du peuple du Québec

- Abrogation de l'Acte de l'Amérique du Nord Britannique [AANB]! 
[16]
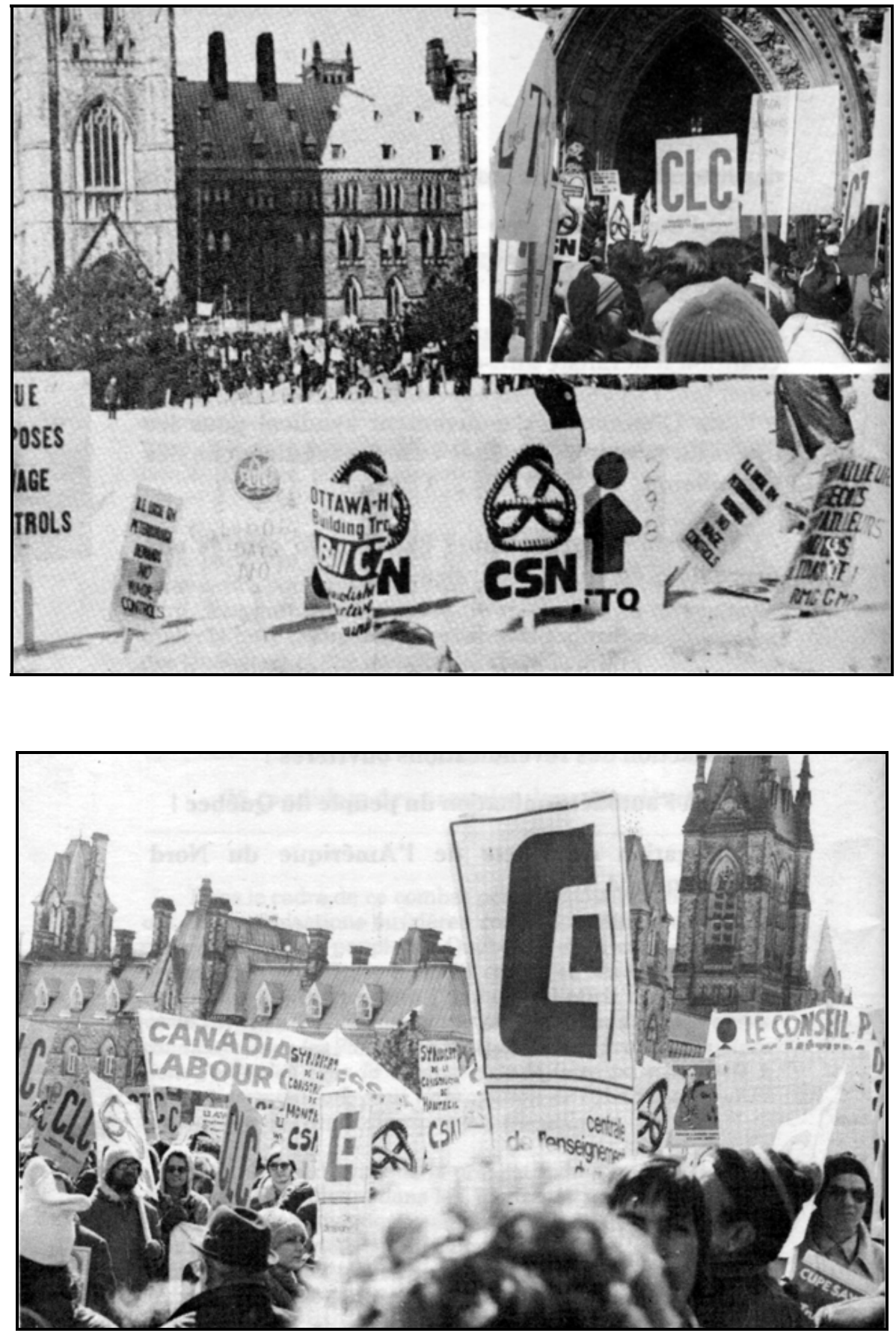

Le 22 mars 1976, les travailleurs de toutes les régions du Canada, dans un même mouvement, manifestent contre le gouvernement Trudeau, contre les attaques de l'État fédéral centralisateur et oppresseur. 